\title{
Papers
}

\section{Operative vaginal delivery and neonatal and infant adverse outcomes: population based retrospective analysis}

Kitaw Demissie, George G Rhoads, John C Smulian, Bijal A Balasubramanian, Kishor Gandhi, K S Joseph, Michael Kramer

\begin{abstract}
Objective To compare the risk of neonatal and infant adverse outcomes between vacuum and forceps assisted deliveries.

Design Population based study.

Setting US linked natality and mortality birth cohort file and the New Jersey linked natality, mortality, and hospital discharge summary birth cohort file.

Participants Singleton live births in the United States $(\mathrm{n}=11639$ 388) and New Jersey $(\mathrm{n}=375$ 351).

Main outcome measures Neonatal morbidity and mortality.

Results Neonatal mortality was comparable between vacuum and forceps deliveries in US births (odds ratio $0.94,95 \%$ confidence interval 0.79 to 1.12 ). Vacuum delivery was associated with a lower risk of birth injuries $(0.69,0.66$ to 0.72$)$, neonatal seizures $(0.78$, 0.68 to 0.90$)$, and need for assisted ventilation $(<30$ minutes $0.94,0.92$ to 0.97 ; $\geq 30$ minutes $0.92,0.88$ to 0.98). Among births in New Jersey, vacuum extraction was more likely than forceps to be complicated by postpartum haemorrhage (1.22, 1.07 to 1.39$)$ and shoulder dystocia (2.00, 1.62 to 2.48$)$. The risks of intracranial haemorrhage, difficulty with feeding, and retinal haemorrhage were comparable between both modes of delivery. The sequential use of vacuum and forceps was associated with an increased risk of need for mechanical ventilation in the infant and third and fourth degree perineal tears.

Conclusion Although vacuum extraction does have risks, it remains a safe alternative to forceps delivery.
\end{abstract}

\section{Introduction}

Vacuum extraction and obstetric forceps are operative procedures used during complicated vaginal deliveries. They are indicated for cord prolapse, a non-reassuring fetal heart rate, prolonged second stage labour, intrapartum haemorrhage, exhaustion, and heart disease, pulmonary injury, and certain neurological conditions in the mother. ${ }^{12}$ The use of vacuum extraction relative to forceps has increased in the United States, accounting for $68 \%$ of all operative vaginal deliveries in 2000-an increase from $41 \%$ in $1990 .{ }^{3}$ This increase, however, has been accompanied by reports to the US Food and Drug Administration of fetal deaths and serious injuries. ${ }^{4}$
In 1998, the FDA released a warning that vacuum assisted deliveries may result in fatal complications, particularly subgaleal haematoma and intracranial haemorrhage (including subdural, subarachnoid, intraventricular, and intraparenchymal haemorrhage). ${ }^{4} \mathrm{We}$ undertook a population based study to compare the risk of neonatal morbidities and mortality between deliveries by vacuum extraction and forceps.

\section{Materials and methods}

\section{Birth cohorts}

Our data were derived from two sources: the Center for Disease Control's linked natality and mortality birth cohort file for the United States, 1995-8; and the linked natality, mortality, and hospital discharge summary birth cohort file for New Jersey, $1989-93 .^{56}$ The linked cohort file for New Jersey was not available for recent years.

\section{United States file}

The Center for Disease Control's linked file is produced annually and includes data from birth and death certificates provided by individual states under the Vital Statistics Cooperative Program. Because a large study size is needed to study mortality as an end point, we used data from the US file to examine neonatal deaths (0-27 days) and infant deaths (0-364 days). Neonatal morbidities were also examined, including birth injuries (facial nerve injury, intracranial haemorrhage, haematoma of internal organs, and bone fractures), seizures, and receipt of assisted ventilation ( $<30$ minutes and $\geq 30$ minutes). The reporting of operative vaginal deliveries from birth certificates has shown a moderate to high sensitivity compared with hospital records. ${ }^{78}$

\section{New Jersey file}

The New Jersey file contains linked information on birth certificates, infant death certificates, and maternal and newborn hospital discharge summaries. Linkage of the hospital discharge summaries to birth certificates permitted examination of additional outcomes for neonatal morbidity, including cephalohaematoma, intracranial haemorrhage (subdural or cerebral haemorrhage, intraventricular haemorrhage, and subarachnoid haemorrhage), shoulder dystocia,
Division of Epidemiology, University of Medicine and Dentistry of New Dentistry of New Jersey, School of
Public Health, 683 Hoes Lane West, PO Box 9,

Piscataway,

NJ 08854, USA

Kitaw Demissie

assistant professor

George G Rhoads professor

Bijal A

Balasubramanian

research associate

Kishor Gandhi graduate student

Division of

Maternal Foetal Medicine,

Department of

Obstetrics and

Gynaecology and

Reproductive

Sciences, University

of Medicine and

Dentistry of New

Jersey, Robert

Wood Johnson

Medical School,

New Brunswick,

NJ 08901, USA

John C Smulian

associate professor

Perinatal

Epidemiology

Research Unit,

Department of

Obstetrics and

Gynaecology and

Paediatrics,

Dalhousie

University, Halifax,

NS, Canada

B3H 4N1

K S Joseph

associate professor

Department of

Paediatrics, McGill

University, Faculty

of Medicine,

Montreal, QC,

Canada H3G 1Y6

Michael Kramer

professor

Correspondence to:

K Demissie

demisski@umdnj.edu 
Table 1 Maternal and infant risk factors by mode of delivery. Values are numbers (percentages)

\begin{tabular}{|c|c|c|c|c|c|c|c|}
\hline \multirow[b]{2}{*}{ Risk factors } & \multicolumn{3}{|c|}{ Deliveries in United States (1995-8) } & \multicolumn{4}{|c|}{ Deliveries in New Jersey (1989-93) } \\
\hline & $\begin{array}{c}\text { Unassisted } \\
(n=10137144)\end{array}$ & $\begin{array}{c}\text { Forceps } \\
(\mathrm{n}=435339)\end{array}$ & $\begin{array}{c}\text { Vacuum } \\
(\mathrm{n}=891340)\end{array}$ & $\begin{array}{l}\text { Unassisted } \\
\text { ( } n=327 \text { 373) }\end{array}$ & $\begin{array}{c}\text { Forceps } \\
(\mathrm{n}=26 \text { 491) }\end{array}$ & $\begin{array}{c}\text { Vacuum } \\
(n=19120)\end{array}$ & $\begin{array}{c}\text { Vacuum plus } \\
\text { forceps }(n=1889)\end{array}$ \\
\hline \multicolumn{8}{|l|}{ Maternal factors } \\
\hline \multicolumn{8}{|l|}{$\operatorname{Age}^{*}:$} \\
\hline$<20$ & $1372658(13.5)$ & $63640(14.6)$ & $129062(14.5)$ & $32563(10.0)$ & $1659(6.3)$ & $1842(9.6)$ & $133(7.1)$ \\
\hline $20-24$ & $2613107(25.8)$ & $104528(24.0)$ & $208926(23.4)$ & $68674(21.0)$ & $4160(15.7)$ & $3792(19.8)$ & $347(18.4)$ \\
\hline $25-29$ & $2793585(27.6)$ & $126264(29.0)$ & 253795 (28.5) & $101331(31.0)$ & $9489(35.8)$ & $6250(32.7)$ & $661(35.0)$ \\
\hline $30-34$ & $2236445(22.1)$ & $95513(21.9)$ & $201388(22.6)$ & $89059(27.2)$ & $8098(30.6)$ & $5118(26.8)$ & $543(28.8)$ \\
\hline$\geq 35$ & $1121349(11.1)$ & $45394(10.4)$ & $98169(11.0)$ & $35509(10.9)$ & $3073(11.6)$ & $2110(11.0)$ & $203(10.8)$ \\
\hline \multicolumn{8}{|l|}{ Race: } \\
\hline White & 8062451 (79.5) & 365418 (83.9) & 747107 (83.8) & $194971(59.6)$ & $20793(78.5)$ & $12928(67.6)$ & 1446 (76.6) \\
\hline Black & $1540533(15.2)$ & $49328(11.3)$ & $86516(9.7)$ & $63049(19.3)$ & $2332(8.8)$ & $2551(13.3)$ & $188(10.0)$ \\
\hline Other & $534160(5.3)$ & $20593(4.7)$ & $57717(6.5)$ & $69353(21.2)$ & $3366(12.7)$ & $3641(19.0)$ & $255(13.5)$ \\
\hline \multicolumn{8}{|l|}{ Parity*: } \\
\hline Nulliparous & 3744621 (36.9) & $307533(70.6)$ & $566200(63.5)$ & $125828(38.4)$ & $18370(69.3)$ & $12313(64.4)$ & 1439 (76.1) \\
\hline Multiparous & $6340340(62.6)$ & $125690(29.0)$ & $320345(35.9)$ & $195263(59.7)$ & $7590(28.7)$ & $6404(33.5)$ & $424(22.5)$ \\
\hline \multicolumn{8}{|l|}{ Disorders: } \\
\hline Diabetes mellitus & $206951(2.0)$ & $11113(2.6)$ & 20319 (2.3) & $6159(1.9)$ & $470(1.8)$ & $359(1.9)$ & $42(2.2)$ \\
\hline Prepregnancy hypertension & $49845(0.5)$ & $2742(0.6)$ & $4953(0.6)$ & $2641(0.8)$ & $211(0.8)$ & $163(0.9)$ & $10(0.5)$ \\
\hline $\begin{array}{l}\text { Pregnancy induced } \\
\text { hypertension }\end{array}$ & $265632(2.6)$ & $19414(4.5)$ & $35576(4.0)$ & 11506 (3.5) & $1111(4.2)$ & $995(5.2)$ & $100(5.3)$ \\
\hline \multicolumn{8}{|l|}{ Neonatal factors } \\
\hline \multicolumn{8}{|l|}{ Gestational age (weeks): } \\
\hline $35-36$ & $607120(6.0)$ & $21624(5.0)$ & $42828(4.8)$ & $13298(4.1)$ & $737(2.8)$ & $527(2.8)$ & $41(2.2)$ \\
\hline $37-38$ & 2362731 (23.3) & $89011(20.5)$ & 188664 (21.2) & $57444(17.6)$ & $3472(13.1)$ & $2797(14.6)$ & $276(14.6)$ \\
\hline $39-40$ & 4991664 (49.2) & $217312(49.9)$ & $448030(50.3)$ & $203460(62.2)$ & $16685(63.0)$ & $11781(61.6)$ & $1152(61.0)$ \\
\hline $41-42$ & 1739305 (17.2) & $88329(20.3)$ & $173243(19.4)$ & $52384(16.0)$ & $5507(20.8)$ & $3974(20.8)$ & $418(22.1)$ \\
\hline$>42$ & $436324(4.3)$ & $19063(4.4)$ & $38575(4.3)$ & $787(0.2)$ & $90(0.3)$ & $41(0.2)$ & $2(0.1)$ \\
\hline \multicolumn{8}{|l|}{ Birth weight $(\mathrm{g})^{\star}$ : } \\
\hline$<1500$ & $4314(0)$ & $105(0)$ & $135(0)$ & $173(0.1)$ & $5(0)$ & $5(0)$ & $0(0)$ \\
\hline 1500-2499 & $349550(3.5)$ & $11295(2.6)$ & $21056(2.4)$ & 11449 (3.5) & $644(2.4)$ & $411(2.2)$ & $30(1.6)$ \\
\hline 2500-3999 & 8815485 (87.0) & 347627 (86.1) & 774612 (86.9) & $283075(86.6)$ & $22612(85.4)$ & $16593(86.8)$ & 1608 (85.1) \\
\hline$>4000$ & $967795(9.6)$ & $49312(11.3)$ & $95537(10.7)$ & $32032(9.8)$ & 3179 (12.0) & $2079(10.8)$ & $246(13.0)$ \\
\hline
\end{tabular}

${ }^{*}$ Results may not add to $100 \%$ because of missing values.

facial nerve injury, feeding difficulty, and retinal haemorrhage. The file also allowed a detailed comparison of labour complications that are likely to influence outcomes of deliveries by forceps or vacuum extraction. These complications included disproportion, malposition at onset of labour, obstruction by bony pelvis, deep transverse arrest and persistent occipitoposterior position, and other causes of obstructed labour; primary, secondary, and other uterine inertia; precipitate labour; hypertonic, incoordinate, or prolonged uterine contraction; long labour; and complications due to the umbilical cord. We were also able to examine selected maternal outcomes, including third and fourth degree perineal tears and postpartum haemorrhage. Cases concerning sequential use of vacuum and forceps were also identified. Information from hospital discharge summaries and birth certificates were used to define complications, obstetric procedures, and outcomes. Linked data were more complete for mode of delivery and maternal and fetal complications than for birth certificates alone. ${ }^{7-9}$

\section{Participants}

We analysed mother-infant pairs from the US and New Jersey files if they concerned singleton live births. Exclusions were caesarean or breech deliveries, infants with congenital malformations, or infants born at less than 35 weeks' gestation (at this age delivery is a relative contraindication for vacuum extraction). ${ }^{10}$

Mode of delivery (unassisted vaginal, vacuum, or forceps) was the independent variable of interest in both analyses. Potential determinants or confounders of mortality and morbidity were personal characteristics (maternal age, race, and education), risk factors associated with pregnancy (gestational age, parity, birth weight, diabetes mellitus, gestational diabetes, chronic hypertension, pregnancy induced hypertension), and labour complications (premature rupture of membranes, induction of labour, fetal distress, placental abruption, and intrapartum bleeding).

\section{Statistical analysis}

We examined the association between infant mortality and morbidity and mode of delivery using logistic regression models. Odds ratios and 95\% confidence intervals were estimated before and after adjusting for confounders. We performed a post hoc power calculation ${ }^{11}$ based on an $\alpha$ of 0.05 , sample size of 435339 for the forceps group and 891340 for the vacuum group, and a neonatal mortality of 5 per 10000 deliveries for the forceps group. Our study had $92 \%$ and $81 \%$ power to detect $30 \%$ and $25 \%$ differences in neonatal mortality between forceps and vacuum deliveries, respectively. All analyses were performed using SAS.

\section{Results}

Overall, there were 15189537 singleton live births in the United States during 1995-8 and 556597 in New Jersey during 1989-93. Vacuum extraction and forceps accounted for $7.4 \%$ and $4.4 \%$, respectively, of all US deliveries in $1995,7.8 \%$ and $4.0 \%$ in $1996,7.8 \%$ and 
Table 2 Complications of labour among deliveries in New Jersey, 1989-93. Values are numbers (percentages)

\begin{tabular}{|c|c|c|c|c|}
\hline Complication & $\begin{array}{l}\text { Unassisted } \\
(\mathrm{n}=327 \text { 373) }\end{array}$ & $\begin{array}{c}\text { Forceps } \\
(\mathrm{n}=26 \text { 491) }\end{array}$ & $\begin{array}{l}\text { Vacuum } \\
(n=19120)\end{array}$ & $\begin{array}{l}\text { Vacuum plus forceps } \\
(\mathrm{n}=1889)\end{array}$ \\
\hline Premature rupture of membranes & $19330(5.9)$ & $1927(7.3)$ & 1251 (6.5) & $160(8.5)$ \\
\hline Disproportion & $253(0.1)$ & $100(0.4)$ & $33(0.2)$ & $7(0.4)$ \\
\hline \multicolumn{5}{|l|}{ Obstructed labour: } \\
\hline Malposition at onset of labour & $49(0.0)$ & $30(0.1)$ & $14(0.1)$ & $1(0.1)$ \\
\hline Obstruction by bony pelvis & $6(0.0)$ & $22(0.1)$ & $7(0.0)$ & $2(0.1)$ \\
\hline Deep transverse arrest and persistent occipitoposterior position & $532(0.2)$ & $585(2.2)$ & $247(1.3)$ & $63(3.3)$ \\
\hline Other causes & $10(0.0)$ & $40(0.2)$ & $5(0.0)$ & $3(0.2)$ \\
\hline \multicolumn{5}{|l|}{ Abnormal forces of labour: } \\
\hline Primary uterine inertia & $2987(0.9)$ & $387(1.5)$ & $349(1.8)$ & $49(2.6)$ \\
\hline Secondary uterine inertia & $1810(0.6)$ & $640(2.4)$ & $335(1.8)$ & $52(2.8)$ \\
\hline Other uterine inertia & $7897(2.4)$ & $926(3.5)$ & $679(3.6)$ & $66(3.5)$ \\
\hline Precipitate labour & $8763(2.7)$ & $117(0.4)$ & $141(0.7)$ & $8(0.4)$ \\
\hline Hypertonic labour, incoordinate or prolonged uterine contraction & $298(0.1)$ & $50(0.2)$ & $43(0.2)$ & $10(0.5)$ \\
\hline Long labour & $3342(1.0)$ & $1320(5.0)$ & $870(4.6)$ & $141(7.5)$ \\
\hline \multicolumn{5}{|l|}{ Umbilical cord: } \\
\hline Prolapse & $1129(0.3)$ & $173(0.7)$ & $90(0.5)$ & $19(1.0)$ \\
\hline Tight around neck* & $10290(3.1)$ & $791(3.0)$ & $736(3.8)$ & $67(3.5)$ \\
\hline Entanglement with and without compression* & $53352(16.3)$ & $5327(20.1)$ & $3413(17.9)$ & $357(18.9)$ \\
\hline Other $^{*}$ & $946(0.3)$ & $88(0.3)$ & $71(0.4)$ & $9(0.5)$ \\
\hline Induction of labour & $33509(10.2)$ & $2940(11.1)$ & $2820(14.7)$ & $311(16.5)$ \\
\hline Placental abruption & $1175(0.4)$ & $217(0.8)$ & $109(0.6)$ & $17(0.9)$ \\
\hline Intrapartum bleeding & $927(0.3)$ & $89(0.3)$ & $80(0.4)$ & $8(0.4)$ \\
\hline Fetal distress & $4974(1.5)$ & $1508(5.7)$ & $1118(5.8)$ & $166(8.8)$ \\
\hline
\end{tabular}

*Diagnoses after birth.

$3.6 \%$ in 1997 , and $7.6 \%$ and $3.2 \%$ in 1998 . The values for New Jersey were $2.5 \%$ and $6.4 \%$ in $1989,3.2 \%$ and $5.7 \%$ in $1990,3.8 \%$ and $5.0 \%$ in $1991,4.4 \%$ and $4.6 \%$ in 1992, and $4.9 \%$ and $4.1 \%$ in 1993 . This represents a $96 \%$ relative increase in the use of vacuum assisted deliveries from 1989 to 1993.

Our inclusion criteria were met by 11639388 births in the United States and 375351 births in New Jersey. Table 1 shows the distribution of maternal and infant risk factors by mode of delivery. The mothers in New Jersey were more likely to be older than US mothers. Nulliparous women were more likely to deliver by either vacuum or forceps than parous women. The frequency of diabetes mellitus and intrapartum bleeding was slightly higher among the US mothers, whereas hypertensive disorders of pregnancy and placental abruption were slightly higher among the New Jersey mothers. These rates were similar for both modes of delivery. Fetal distress was more common among instrumental deliveries. The distribution for gestational age was similar between infants delivered by forceps and those delivered by vacuum in both cohorts. The proportion of infants born at lower gestational ages was, however, higher for the United States. This is likely due to the increasing trend of preterm birth during the past few years; data for US births are more recent than those for New Jersey births.

Table 2 shows the rates of labour complications by mode of delivery among New Jersey births. The frequency of complications was comparable between vacuum and forceps deliveries but was more common in the small number of cases when vacuum and forceps were used sequentially.

Table 3 shows the risks of neonatal mortality and morbidity associated with mode of delivery for US births. After adjusting for important confounders, the risk of neonatal mortality was similar between infants delivered by vacuum or forceps. Because of the strong association between parity and mode of delivery, we carried out separate analyses for nulliparous and parous mothers. The results of these analyses were similar to the overall (unstratified) results. For instance, among nulliparous women the risk of neonatal mortality for vacuum deliveries compared with forceps deliveries was similar to the risk among parous women (odds ratio $0.95,95 \%$ confidence interval 0.76 to 1.18 and $0.93,0.69$ to 1.27 , respectively). The risk of infant mortality was also similar between these two groups ( $0.91,0.81$ to 1.04 and $0.83,0.71$ to 0.97 , respectively). The risks of birth injuries and neonatal seizures were lower for vacuum deliveries.

In New Jersey births, cephalohaematoma was more common among infants delivered by vacuum, and

Table 3 Neonatal and infant mortality and morbidity by mode of delivery in United States, 1995-8. Values are number (incidence) unless stated otherwise

\begin{tabular}{|c|c|c|c|}
\hline & $\begin{array}{c}\text { Unassisted } \\
(\mathrm{n}=10137144)\end{array}$ & $\begin{array}{c}\text { Forceps } \\
(\mathrm{n}=435339)\end{array}$ & $\begin{array}{c}\text { Vacuum } \\
(\mathrm{n}=891340)\end{array}$ \\
\hline \multicolumn{4}{|l|}{ Mortality } \\
\hline Neonatal death ${ }^{\star} \dagger:$ & $3741(3.7)$ & $218(5.0)$ & $416(4.7)$ \\
\hline Adjusted odds ratio $(95 \% \mathrm{Cl}) \ddagger$ & 0.75 (0.64 to 0.87 ) & 1.00 & 0.94 (0.79 to 1.12$)$ \\
\hline Infant death§ & $18303(18.1)$ & $714(16.4)$ & $1316(15.8)$ \\
\hline Adjusted odds ratio $(95 \% \mathrm{Cl})$ & 0.87 (0.80 to 0.94$)$ & 1.00 & 0.88 (0.79 to 0.96$)$ \\
\hline \multicolumn{4}{|l|}{ Morbidity } \\
\hline Birth injuries: & $21729(21.4)$ & $4751(109.1)$ & $6783(76.1)$ \\
\hline Adjusted odds ratio $(95 \% \mathrm{Cl})$ & 0.25 (0.24 to 0.26$)$ & 1.00 & 0.69 (0.66 to 0.72$)$ \\
\hline Neonatal seizures: & $5119(5.0)$ & $380(8.7)$ & $581(6.5)$ \\
\hline Adjusted odds ratio $(95 \% \mathrm{Cl})$ & 0.75 (0.67 to 0.84$)$ & 1.00 & $0.78(0.68$ to 0.90$)$ \\
\hline \multicolumn{4}{|l|}{ Assisted ventilation } \\
\hline$<30$ minutes: & $148478(146.5)$ & $12753(292.9)$ & $22298(250.2)$ \\
\hline Adjusted odds ratio $(95 \% \mathrm{Cl})$ & 0.66 (0.65 to 0.67$)$ & 1.00 & $0.94(0.92$ to 0.97$)$ \\
\hline$\geq 30$ minutes: & $26286(25.9)$ & $2405(55.2)$ & $4246(47.6)$ \\
\hline Adjusted odds ratio (9 & 0.61 (0.58 to 0.64$)$ & 1.00 & 0.92 \\
\hline
\end{tabular}

*Death within 0-27 days.

†Number per 10000 deliveries.

łAdjusted for maternal age, race, parity, education, gestational age, birth weight, diabetes, pre-existing hypertension, pregnancy induced hypertension, premature rupture of membranes, induction of labour, fetal distress, placental abruption, and intrapartum bleeding.

§Death within 0-364 days. 
Table 4 Neonatal and maternal morbidity by mode of delivery in New Jersey, 1989-93. Values are number (incidence) unless stated otherwise

\begin{tabular}{|c|c|c|c|c|}
\hline & $\begin{array}{l}\text { Unassisted } \\
\text { ( } \mathrm{n}=327 \text { 373) }\end{array}$ & $\begin{array}{l}\text { Forceps } \\
(\mathrm{n}=26 \mathrm{491})\end{array}$ & $\begin{array}{l}\text { Vacuum } \\
(n=19120)\end{array}$ & $\begin{array}{l}\text { Vacuum plus forceps } \\
\qquad(\mathrm{n}=1889)\end{array}$ \\
\hline \multicolumn{5}{|l|}{ Neonatal morbidity } \\
\hline Cephalohaematoma* $^{*}$ & $5457(166.7)$ & $1681(634.6)$ & $2135(1116.6)$ & $257(1360.5)$ \\
\hline Facial nerve injury & $78(2.4)$ & $98(37.0)$ & $10(5.2)$ & $10(52.9)$ \\
\hline Intracranial haemorrhage & $122(3.7)$ & $45(17.0)$ & $31(16.2)$ & $5(26.5)$ \\
\hline Adjusted odds ratio $(95 \% \mathrm{Cl}) \dagger$ & 0.29 (0.20 to 0.41$)$ & 1.00 & 0.96 (0.62 to 1.52$)$ & 1.35 (0.53 to 3.42$)$ \\
\hline Shoulder dystocia & $1464(44.7)$ & $145(54.7)$ & $216(113.0)$ & $12(63.5)$ \\
\hline Adjusted odds ratio $(95 \% \mathrm{Cl})$ & 0.71 (0.59 to 0.85$)$ & 1.00 & 2.00 (1.62 to 2.48$)$ & 1.10 (0.59 to 2.03$)$ \\
\hline Feeding difficulty & $763(23.3)$ & $68(25.7)$ & $57(29.8)$ & $6(31.8)$ \\
\hline Adjusted odds ratio $(95 \% \mathrm{Cl})$ & 0.89 (0.69 to 1.15$)$ & 1.00 & $1.15(0.80$ to 1.64$)$ & 1.23 (0.53 to 2.84$)$ \\
\hline Mechanical ventilation & $768(23.5)$ & $83(31.3)$ & $77(40.3)$ & $14(74.1)$ \\
\hline Adjusted odds ratio $(95 \% \mathrm{Cl})$ & 0.84 (0.66 to 1.06$)$ & 1.00 & 1.27 (0.92 to 1.74$)$ & 2.22 (1.24 to 3.97$)$ \\
\hline Retinal haemorrhage & $597(18.2)$ & $51(19.3)$ & $30(15.7)$ & $6(31.8)$ \\
\hline Adjusted odds ratio $(95 \% \mathrm{Cl})$ & 0.87 (0.65 to 1.18$)$ & 1.00 & 0.78 (0.50 to 1.24$)$ & 1.65 (0.71 to 3.86$)$ \\
\hline \multicolumn{5}{|l|}{ Maternal morbidity } \\
\hline Third degree perineal tear & 12359 (377.5) & 3316 (1251.7) & $1840(962.3)$ & $295(1561.7)$ \\
\hline Adjusted odds ratio $(95 \% \mathrm{Cl})$ & 0.39 (0.38 to 0.41$)$ & 1.00 & 0.78 (0.73 to 0.83$)$ & 1.21 (1.06 to 1.38$)$ \\
\hline Fourth degree perineal tear & $6626(202.4)$ & $2584(975.4)$ & $1199(627.1)$ & $251(1328.7)$ \\
\hline Adjusted odds ratio $(95 \% \mathrm{Cl})$ & 0.28 (0.27 to 0.30$)$ & 1.00 & 0.64 (0.60 to 0.69$)$ & 1.33 (1.15 to 1.53$)$ \\
\hline Postpartum haemorrhage & $4734(144.6)$ & $517(195.1)$ & $458(239.5)$ & $43(227.6)$ \\
\hline Adjusted odds ratio $(95 \% \mathrm{Cl})$ & 0.79 (0.72 to 0.87$)$ & 1.00 & 1.22 (1.07 to 1.39$)$ & 1.12 (0.81 to 1.55$)$ \\
\hline
\end{tabular}

*Number of cases per 10000 deliveries

†Adjusted for birth weight, gestational age, deep transverse arrest, persistent occipitoposterior position, long labour, fetal distress, cord prolapse, placental abruption, and intrapartum bleeding.

facial nerve injury was more common among those delivered by forceps (table 4). After adjusting for confounders, the risk of shoulder dystocia among infants delivered by vacuum was twofold higher than those delivered by forceps. The risks of intracranial haemorrhage or retinal haemorrhage, feeding difficulties, or need for mechanical ventilation were similar between both modes of delivery. Vacuum extraction carried a slightly lower risk of third and fourth degree perineal tears. The results of stratified analyses by parity did not differ meaningfully from the unstratified analyses (data not shown).

After adjusting for confounders, sequential use of vacuum and forceps compared with forceps alone was associated with an increased risk of need for mechanical ventilation and third and fourth degree perineal tears. In the New Jersey cohort, 523 failed forceps deliveries and 412 failed vacuum deliveries resulted in caesarean section. Of the failed forceps deliveries, two infants each had intracranial haemorrhage and feeding difficulties compared with three cases each for failed vacuum deliveries. Seven infants who were delivered by caesarean section after a failed forceps delivery required mechanical ventilation compared with two infants after a failed vacuum delivery.

Our study included preterm infants (35-36 weeks' gestation) and those at term ( $>34$ weeks). As severe morbidities such as intracranial haemorrhage are more common among preterm infants, we reanalysed the data after their exclusion. The results for term infants were similar to the main analyses for both populations-for example, the odds of mortality during the neonatal period for US infants delivered by vacuum compared with forceps was 0.95 (0.78 to 1.14). In New Jersey, the odds of intracranial haemorrhage for infants delivered by vacuum compared with forceps was $0.96(0.59$ to 1.55$)$.

\section{Discussion}

Delivery by vacuum extraction is at least as safe as delivery by forceps. Fatal complications and outcomes (neonatal death and intracranial haemorrhage) were similar between neonates and infants from two large birth cohorts in the United States after delivery by forceps or vacuum extraction. The risk of birth injuries, neonatal seizures, and third and fourth degree perineal tears were lower for vacuum deliveries. The higher risk of such tears among forceps deliveries was further increased when vacuum and forceps were used sequentially. The risks of developing shoulder dystocia and postpartum haemorrhage were higher for vacuum deliveries.

Vacuum extraction versus forceps assisted delivery The consistency of results from two data sources covering different periods adds credibility to our conclusion that vacuum extraction is at least as safe as forceps. Although delayed second stage of labour is the general indication for use of either procedure, there may be differences in selection of cases affecting comparability. A randomised controlled design would have avoided this problem; however, a study large enough to examine neonatal mortality would be costly, and the results might not reflect the manner in which assisted deliveries are done in the community. In the New Jersey cohort, detailed information on labour complications was available from hospital discharge summaries. We believe that the extensive control of these variables minimised the problem of confounding by indication. Overall, the relatively low rates of fatal complications observed among vacuum deliveries argue against the warning provided by the FDA.

Studies have compared several neonatal outcomes between forceps and vacuum deliveries. ${ }^{12-23}$ A metaanalysis that summarised the results of seven studies found that the risk of cephalohaematoma was higher 
with vacuum deliveries whereas retinal haemorrhage was lower with forceps deliveries. ${ }^{2}$ Because of the requirement for a large sample size, infant mortality, particularly in neonates, has not been compared between the two modes of delivery. In Johanson's meta-analysis of seven studies, only three perinatal deaths occurred among 901 vacuum deliveries and four among 899 forceps deliveries. ${ }^{2}$ Thus the results were inconclusive. Our analysis was based on more than 10 million singleton live births. Our study had sufficient power to detect important differences in deaths among the two modes of delivery, and our results are population based and generalisable.

Studies from California and Quebec have examined the rates of intracranial haemorrhage by mode of delivery. ${ }^{12}$ The California study was restricted to singleton live born infants to nulliparous women; both forceps and vacuum extraction were associated with an increased risk of intracranial haemorrhage. ${ }^{14}$ In the Canadian study only vacuum extraction was associated with subarachnoid haemorrhage. ${ }^{12}$ (This finding was based on a small number of cases, and the increased risk had a wide confidence interval.)

\section{Assisted vaginal deliveries using multiple instruments}

Difficult deliveries in which vacuum was followed by forceps, or either procedure was followed by caesarean section, had worse outcomes than procedures that were successful on the first attempt. Although difficult labour rather than mode of delivery may have been responsible for this, an excessive number of pulls during attempted instrumental deliveries or use of multiple instruments cannot be excluded. In a cohort of over 10000 deliveries in the United Kingdom, the use of multiple instruments and more than three pulls at attempted instrumental delivery were associated with increased neonatal trauma. ${ }^{24}$

\section{Limitations}

Our study has limitations that are inherent in the use of birth certificates and administrative data. Indications and complications of operative vaginal deliveries (defined by codes from the international classification of disease, ninth revision) may not have been captured accurately on hospital discharge summaries, resulting in residual confounding. Also, the occurrence of birth injuries and some other neonatal morbidities are likely to be underestimated. Consequently, our findings on morbidity are likely to be conservative. Nonetheless, our results agree with previous reports on the association between neonatal morbidity and mode of delivery. ${ }^{12} 14$ The experience of the operator may also determine the outcome of delivery. ${ }^{24}{ }^{25}$ The data do not, however, capture such information. Encouraging operative vaginal deliveries may help to reduce the rates of caesarean section. ${ }^{26}$ Emerging evidence suggests an advantage of instrumental vaginal deliveries over caesarean section for subsequent outcomes. ${ }^{27}$

Although delivery by vacuum extraction does have risks, it remains a safe alternative to forceps delivery. Our results underscore the need for obstetric standards in performing instrumental deliveries.

Contributors: KD designed the study, contributed to the analysis, interpreted the results, and wrote the manuscript. KG analysed the US file as part of his fieldwork project for MPH degree. $\mathrm{BAB}$ reanalysed the data after combining information

\section{What is already known on this topic}

A meta-analysis was too small to provide conclusive evidence of the risk of neonatal morbidity between forceps and vacuum deliveries

\section{What this study adds}

Evidence from two large birth cohorts shows that infants delivered by forceps or vacuum are at similar risk of mortality

from both the US and New Jersey files and addressed reviewer's comments. JCS, GGR, KSJ, and MK contributed to the design and write up of the manuscript. KD will act as guarantor for the paper.

Funding: None.

Competing interests: None declared.

Ethical approval: The study was approved by the University of Medicine and Dentistry of New Jersey-Robert Wood Johnson Medical School's Institutional Review Board.

Cunningham F, MacDonald P, Grant N, Leveno KJ, Gilstrap LI, Hankins $\mathrm{G}$, et al. William's obstetrics, 21 ed. New York, NY: McGraw-Hill, 2001.

Johanson RB, Menon BK. Vacuum extraction versus forceps for assisted Johanson RB, Menon BK. Vacuum extraction versus forceps for
vaginal delivery. Cochrane Database Syst Rev 2000;(2):CD000224.

Kozak LJ, Weeks JD. US trends in obstetric procedures, 1990-2000. Birth 2002;29:157-61.

4 US Food and Drug Administration. Public Health Advisory: need for caution when using vacuum assisted delivery devices. Rockville, MD: FDA Center for Devices and Radiological Health, 1998.

5 National Center for Health Statistics. 1995-1999 Linked birth/infant death dataset. Hyattsville, MD: US Department of Health and Human Services, Centers for Disease Control and Prevention. (NCHS CD-Rom Series 20, Nos 12-14.)

6 Demissie K, Breckenridge MB, Rhoads GG. Infant and maternal outcomes in the pregnancies of asthmatic women. Am J Respir Crit Care Med 1998:158:1091-5.

7 Parrish KM, Holt VL, Connell FA, Williams B, LoGerfo JP. Variations in the accuracy of obstetric procedures and diagnoses on birth records in Washington State, 1989. Am J Epidemiol 1993;138:119-27.

8 Piper JM, Mitchel EF Jr, Snowden M, Hall C, Adams M, Taylor P. Validation of 1989 Tennessee birth certificates using maternal and newborn hospital records. Am J Epidemiol 1993;137:758-68.

9 Green DC, Moore JM, Adams MM, Berg CJ, Wilcox LS, McCarthy BJ. Are we underestimating rates of vaginal birth after previous cesarean birth? The validity of delivery methods from birth certificates. Am J Epidemiol 1998;147:581-6.

10 Royal College of Obstetricians and Gynaecologists. Instrumental vaginal delivery. London: RCOG, 2000. (Clinical Green Top Guideline No 26.)

11 Schlesselman JJ. Sample size requirements in cohort and case-control studies of disease. Am J Epidemiol 1974;99:381-4.

12 Wen SW, Liu S, Kramer MS, Marcoux S, Ohlsson A, Sauve R, et al. Comparison of maternal and infant outcomes between vacuum extraction and forceps deliveries. Am J Epidemiol 2001;153:103-7.

13 Vacca A, Grant A, Wyatt G, Chalmers I. Portsmouth operative delivery trial: a comparison between vacuum extraction and forceps delivery. $\mathrm{BrJ}$ Obstet Gynaecol 1983;90:1107-12.

14 Towner D, Castro MA, Eby-Wilkens E, Gilbert WM. Effect of mode of delivery in nulliparous women on neonatal intracranial injury. $N$ Engl $J$ Med 1999:341:1709-14.

15 Punnonen R, Aro P, Kuukankorpi A, Pystynen P. Fetal and maternal effects of forceps and vacuum extraction. Br J Obstet Gynaecol 1986;93:1132-5

16 Johanson R, Pusey J, Livera N, Jones P. North Staffordshire/Wigan assisted delivery trial. BrJ Obstet Gynaecol 1989;96:537-44.

17 Herabutya Y, O-Prasertsawat P, Boonrangsimant P. Kielland's forceps or ventouse-a comparison. Br J Obstet Gynaecol 1988;95:483-7.

18 Hankins GD, Rowe TF. Operative vaginal delivery-year 2000. Am J Obstet Gynecol 1996;175:275-82.

19 Ehlers N, Jensen IK, Hansen KB. Retinal haemorrhages in the newborn. Comparison of delivery by forceps and by vacuum extractor. Acta Ophthalmol (Copenh) 1974;52:73-82.

20 Broekhuizen FF, Washington JM, Johnson F, Hamilton PR. Vacuum extraction versus forceps delivery: indications and complications, 1979 to 1984. Obstet Gynecol 1987;69:338-42.

21 Bofill JA, Rust OA, Schorr SJ, Brown RC, Martin RW, Martin JN Jr, et al. A randomized prospective trial of the obstetric forceps versus the M-cup vacuum extractor. Am J Obstet Gynecol 1996;175:1325-30.

22 Greis JB, Bieniarz J, Scommegna A. Comparison of maternal and fetal effects of vacuum extraction with forceps or cesarean deliveries. Obstet Gynecol 1981:57:571-7.

23 Johanson RB, Rice C, Doyle M, Arthur J, Anyanwu L, Ibrahim J, et al. A randomised prospective study comparing the new vacuum extractor policy with forceps delivery. Br J Obstet Gynaecol 1993;100:524-30.

24 Murphy DJ, Liebling RE, Patel R, Verity L, Swingler R. Cohort study of operative delivery in the second stage of labour and standard of obstetric care. BrJ Obstet Gynaecol 2003;110:610-5. 
25 Murphy DJ, Liebling RE, Verity L, Swingler R, Patel R. Early maternal and neonatal morbidity associated with operative delivery in second stage of labour: a cohort study Lancet 2001·358:1203-7.

26 US Department of Health and Human Services. Understanding and improving health and objectives for improving health. Healthy people 2010. 2nd ed. Washington, DC: US Government Printing Office, 2000.
27 Bahl R, Strachan B, Murphy DJ. Outcome of subsequent pregnancy three years after previous operative delivery in the second stage of labour: cohort study. BMJ 2004;328:311.

(Accepted 5 March 2004) 